\title{
The Multiple Values of 'Botteghe Storiche' Food, Urban Spaces and Memory in Contemporary Milan (Italy)
}

\section{Luca Rimoldi}

PhD in Anthropology, Dipartimento di Sociologia e Ricerca Sociale, Università degli Studi di Milano-Bicocca luca.rimoldi@unimib.it

\section{Doi:10.5901/ajis.2016.v5n1p11}

\section{Abstract}

\begin{abstract}
The term 'Botteghe Storiche' (Historical Workshops) refers to the businesses - operating in retail sales, craft manufacturing, the provision of services or catering - recognised by the City of Milan and listed in the Register of Historical Workshops. This article explores the numerous values that various social actors attribute to the Historical Workshops and focuses on some of the city's restaurants, trattorias and inns. The assumption is that value is not merely an economic factor, created in a commercial relationship, but, in the case of the Historical Workshops, it implies a series of meanings related to aspects of "history", "tradition" and "traditional food", which contribute to the design and creation of urban spaces. Through an analysis of documents, speeches by local politicians, participant observation and ethnographic interviews, the article clarifies the numerous and often contradictory ideas concerning value in these local urban spaces and puts them into perspective.
\end{abstract}

Keywords: Anthropology, Food, Memory, Milan, Italy.

\section{Introduction}

Between November 2014 and June 2015, I conducted ethnographic research with some restaurateurs whose businesses are listed in the Register of Historical Workshops of the City of Milan in order to understand the relationship between what is perceived as "traditional food", the configuration of urban spaces and ideas of social memory in contemporary Milan, as part of a research project financed with a post-doctoral fellowship by the University of Milan-Bicocca for Expo 2015 (Bicocca for Expo Project). My research with the restaurateurs of the Historical Workshops began in the period prior to the opening of Expo Milano 2015. The theme of the World Exposition - Feed the Planet, Energy for Life - has helped stimulate various discussions (academic projects, media reports, etc.) on issues regarding food, its aesthetic, symbolic and cultural importance - in addition to its purely nutritional value - and sustainable, organic and proximity agriculture.

The term Botteghe Storiche (Historical Workshops) refers to businesses or companies - operating in retail sales, craft manufacturing, the provision of services or catering - recognised by the City of Milan since 2005 on the basis of specific criteria and currently listed in the Register of Historical Workshops. The City of Milan laid down the guidelines for the establishment of the Register of Historical Workshops with the approval of Resolution no. 2220 of 5/10/2004. The official tables ${ }^{1}$ of the commercial activities listed in the Register of Historical Workshops of the City of Milan present a total of almost 400 businesses, divided into various merchandise categories, including "clothes shops", "pharmacies", "bakeries", "jewellers", "restaurants", "trattorias", etc.

Issues related to food, its consumption and the connection that emerges with memory have been treated at length, implicitly or explicitly, by anthropological literature (Mintz and Du Bois 2002; Holtzman 2006, Sutton 2001). Human studies in recent years have tended to focus on the link established at a social level between food and the construction of identity (Goody 1998; Montanari 2004), gender identities (Douglas 1985; Appadurai 1988; Counihan 2009; Van Esterik and Counihan 2013) and ideas of class (Rimoldi, 2013), and on how food is viewed in contemporary society as a way of creating new subjectivities (Barberani 2012; Paxon 2013).

This article is based on participant observation, archival research and ethnographic interviews, including the stories of some restaurants, inns and trattorias and their managers. I examine the ideas of "value" and "valorisation" that enrolment in the Register of Historical Workshops of the City of Milan conveys and the types of responses that it

1 The tables can be downloaded from the following website: http://fareimpresa.comune. milano.it/joomla/index.php?/temid=302 (last accessed 5 December 2015). 
produces in the public sphere - of the institutions - and the private or semi-private sphere - of the restaurants.

The semantic boundaries of the ideas of value and valorisation are becoming increasingly less clearly defined today (Graeber 2001). I therefore feel it is worthwhile to try to clarify the numerous and often contradictory ideas on value in this specific local context and put them into perspective, in order to arrive at broader conclusions that transcend the limits of the locality, in which anthropological reflection often becomes embroiled. My starting point is an idea by Daniel Miller (2008), according to whom value may be better understood by considering what it does, rather than what is. In this article I show what value leads the social actors included in my analysis to "do" and "say". I consider work - in a very broad sense - as a source of value, but I present here an analysis of the rhetorics that compose it as a topic of discussion rather than the practical aspects that shape it.

The processing stages through which food products are brought from their places of production to those of consumption are particularly complex. During my research, I observed some of the steps in these long production processes and focused on the final stages: the transformation of a food product (sold by a supplier to a caterer) into dish and the serving of the dish to a customer in a Milanese Historical Workshop restaurant. The values of these exchanges are not only economic - although the economic value is certainly an important factor and creates a division between customers "who can afford" to dine in these restaurants and those who cannot - but are often related in various ways to what could be defined as "an economy of urban memory". In the case of the restaurateurs of the Historical Workshops of the City of Milan, this economy seems to be authorised by the local institution - which recognises the business as an historical asset - and conveyed through the preparation of the food that is served, together with the stories of the restaurants or restaurateurs. Analysis of the economy of urban memory for the restaurateurs and Milanese institutions rather than for consumers - is at the heart of the reflection I present. Restaurants offer a privileged vantage point in this perspective, as noted by Breiss and Sutton (2007), because they allow observation of several of the features of economic life studied by cultural anthropology: forms of exchange, modes of production and the symbolism behind consumption. Moreover, in their words:

\begin{abstract}
Restaurants provide a context in which questions about class, ethnicity, gender and sexuality all play out (...). Moreover, restaurants have become important symbols of postmodern life itself, with chefs transformed into media stars and restaurants increasingly carrying out symbolic work previously reserved for monuments and parades, representing the ethos of cities, regions, ethnic groups and nations. From the sensual and local, to the symbolic and global, restaurants, we believe, constitute ideal total social phenomena for our postmodern world (Breiss and Sutton: 1).
\end{abstract}

The article is divided into two parts. After clarifying what the Register of Historical Workshops of the City of Milan consists of and shedding light on the genesis of a valorisation process from the perspective of the institution, I examine the speeches given or published by the various political exponents involved in the administration and management of the City of Milan from 2005 up to the present with regard to the Historical Workshops and the values ascribed to them. In the second part, I examine the views of the restaurateurs, highlighting how the values presented by the institution are negotiated in the daily running of a business through various practices: the preparation of the food, the presentation of the life stories of parts of the city, and the types of social relationships that come to the fore in the restaurants recognised as Historical Workshops. Although examined separately here for clarity of presentation, it should be noted that the institutional discourses and those of the restaurateurs are in constant dialogue with each other.

\title{
2. Institutional Discourses and the Historical Value
}

The creation of the Register of Historical Workshops of the City of Milan began about ten years ago and, over time, many business owners have applied for recognition of their activities ${ }^{2}$. The initiative has proven to transcend the political orientation of the two successive city councils that have governed the city over the last ten years: the centre-right administration of Mayor Letizia Moratti (2006-2011) and the centre-left administration of Mayor Giuliano Pisapia (2011-

\footnotetext{
${ }^{2}$ For recognition by the Registry of Historical Workshops of Milan, the businesses must possess certain requirements that associate them with particular areas and the owners have to submit a number of documents. The application for participation in the annual call to tender must be delivered by hand or sent in duplicate to the Management Protocol Office, with a series of annexes showing the year in which the business began and its continuity in the period for which recognition is sought. The application and annexes are evaluated by a Technical Committee consisting of a representative of the Trade Department, one from the Street Furniture and Landscaping Department, one from the Urban Planning Department and a representative of the Chamber of Commerce of Milan.
} 
present).

Municipal resolution no. 2220 of $5 / 10 / 2004$ is particularly significant because it shows the requirements for a business to qualify for the Register of Historical Workshops and at the same time determines its status as subject to valorisation. The document states that the purpose for the creation of the Register is to "protect and defend business and craft activities that are deeply rooted within the local urban fabric". These activities are recognised as "cultural assets at risk of extinction".

The choice of the term "bottega" (workshop) is particularly evocative in this respect. The Italian word comes from the Latin "apotheca" which, in turn, derives from the Greek word "ámoӨńkn" (apothếkē - composed of the preposition ámo, indicating a separation and Өńkn meaning storeroom, warehouse). The Italian word "bottega" refers to a room, generally facing the street, in which goods are displayed and sold, and now, by way of extension, also indicates business activities of various kinds related, more or less explicitly, to craft activities. On a first level of analysis, justified by the choice of the noun (workshop) and the adjective (historical), these businesses may be considered part of the category of historical and cultural heritage: the discussions regarding their valorisation could lead them to assume a "semiophorous" value (Pomian 1999). The Historical Workshops seem to be bearers of culture, memory and historical and political significance, and so intervention measures ${ }^{3}$ are necessary to ensure their "survival" within the dynamics of the global capitalist market, from which, however, they remain detached. However, the matter is not so simple, as we shall see.

If in the Middle Ages and the Renaissance the "bottega" was understood as the workshop of artists, writers and painters, and, by extension, of the various people who worked there (assistants, apprentices, etc.), what are the criteria that identify the Historical Workshops of the City of Milan today? The characteristics and requirements of the Register of Historical Workshops seem to partly answer this question. These requirements are described in the city resolution with these words:

1) continuity of the commercial, craft and public establishment activity for a period of not less than fifty years at the time of application;

2) the activity must necessarily involve the same merchandise sector, regardless of any change of ownership; Above all, the importance is stressed of the fact that a business manages to survive in the same merchandise sector for fifty years, despite various economic hardships. The first aspect that is recognised is therefore continuity over time; the fifty-year period is the first condition to be determined. Verification of this requirement is made by cross-checking and seeking correspondence between the data presented in the application for enrolment in the Register and that found in the records of the Chamber of Commerce of Milan, which must be submitted together with the request for Registration. A third requirement:

3 ) the presence of any architectural, decorative or functional features of particular historical, architectural or urban interest, or the overall conservation of the original furnishings.

The ambience of the Historical Workshop should also convey to visitors that sense of timelessness that transpires from the first two requirements for recognition; this aspect is verified by the submission of photographic material. In this regard, however, Donata Radice, an official in charge of the craftwork service and support for businesses and trades of the City of Milan told met:

A further requirement is an architectural quality, in terms of the furniture or furnishings used... but Milanese business people often have little sensibility with regard to this because, particularly in certain decades, renovation was the all the rage. Food-related businesses in particular were subject to renovation, due in part to needs determined by sanitation requirements. So, for example, it is hard to find an old bakery, because they have all been renovated for health and hygiene reasons. There is not very much in terms of furnishings, it is easier perhaps to find something related to the quality of the building, or there might be some historical buildings with columns inside them, or with friezes or beautiful floors... perhaps there is something like this, and so we ask them to document it. (Donata Radice)5.

The words of Donata Radice highlight an initial contradictory aspect of the issue. While, on the one hand, the intention of the Register of Historical Workshops is to preserve the premises or shop in its original state, on the other, the

\footnotetext{
${ }^{3}$ The "Guidelines for the protection and valorisation of the Historical Workshops of Milan" were approved by City Council Resolution No. 3224 of 12/11/2010.

${ }^{4}$ The craft service and support to businesses and trades is part of the Trade Department, Office for Productive Activities, under the Central Directorate for Production Activities and Territorial Marketing of the City of Milan.

5 Interview with Donata Radice, 26 November 2014.
} 
requirement does not allow for the changes and regulations that have transformed daily working practices (and therefore commercial and craft activities) in recent years. In the case of the restaurateurs, these include changes in health and hygiene requirements and the technological advances in the field of professional kitchen appliances and subsequent redistribution of kitchen space.

In short, what makes a workshop "historical" is the fact that it has been preserved in a virtually unchanged state for a minimum period of fifty years. However, the guidelines focus on the businesses - not their managers - as the "objects" of valorisation. Therefore, changes to the management or registered address of the business are permitted, without this implying the "non-historicity" of the "workshop". These aspects presented by the resolution take on a different form in the speeches of the politicians and administrators, whose discourses seem to identify the values of the Historical Workshops with their presence in specific urban areas and being under family management. As the Italian anthropologist Michela Badii states:

Le produzioni tipiche, la riscoperta del territorio, la valorizzazione dell'ambiente appaiono come la valorizzazione di un iperdiscorso, non solo intorno al cibo, che tende a capitalizzare le peculiarità sociali, economiche, culturali e locali sotto il nome di patrimonio, e che assume a tratti toni accesi e talvolta enfatici. Concetti quali 'patrimonio','autenticità', 'tradizione', ritornano nei nostri palinsesti quotidiani con una certa frequenza, tanto da essere accolti nel lessico della sfera del senso comune6 (Badii 2012: 9).

In the case of Historical Workshops of the City of Milan, this "lexical sphere of common sense" has appeared in written form in a series of books. Five volumes were published between 2006 and 2010 entitled "Historical Workshops of Milan"; these books, funded by the City of Milan and the City Chamber of Commerce, contain a collection of descriptions and images from the Register of recognised Historical Workshops. The first page of each volume features the words: "The Historical Workshops: an important element of memory, a valuable testament to culture and tradition, and part of our city's cultural heritage."

An analysis of samples of the texts contained in these publications seems particularly relevant, as they contain some discourses by the Councillors for Productive Activities (Tiziana Maiolo and Giovanni Terzi), the President of the Chamber of Commerce (Carlo Sangalli) and the Mayor (Letizia Moratti) ${ }^{7}$ in which they justify and build on the meanings and values that the Register of Historical Workshops attributes to the businesses. In general, these values are presented under the aegis of the categories of "memory", "culture" and "tradition", and appear as indispensable elements of the "hyperdiscussion" on Historical Workshops. As Tiziana Maiolo comments in the first volume (2006), the Historical Workshops are:

(...) a valuable asset for Milan, on a par with the new economy, the skyscrapers, the Stock Exchange and fashion. (...) they represent life, our own and that of our old people, as well as that of our children (...) The places we refer to are often of modest dimensions, but conceal something beautiful and good. They are the many 'Brambilla' [Milanese family name] that are part of our history (...). [Their atmosphere allows us to] relive a bygone era that is typically Milanese, where nostalgia is a driving force for the present as well as the future. One thing is certain: these realities will still be here tomorrow, and we shall defend them. (...) We are not cultivating the myth of the noble savage, who sits threading beads in his archaic garden while the rest of the world is developing at a rapid pace. We are establishing a symbol of memory that will be an important tourist attraction for Milan as a world capital (Tiziana Maiolo, 2006).

The words of Tiziana Maiolo confirm the idea of the Historical Workshop as being linked to the Milanese origins of its managers ("the many 'Brambilla' that are part of our history"). However, very few of the restaurateurs that I interviewed and observed during my ethnographic survey told me they were of Milanese origin. A large number of the restaurateurs of the Historical Workshops come from Tuscany - in those cases where the restaurants are family-run businesses.

In continuity with the words of Tiziana Maiolo, the speech by Carlo Sangalli - then President of the Chamber of Commerce of Milan - included in the 2006 volume focuses on the idea of origins, tradition and the link with the city

${ }^{6}$ Typical products, the rediscovery of the local territory and enhancement of the environment appear as the valorisation of a hyperdiscourse, not only concerning food, which tends to capitalise on particular social, economic, cultural and local aspects under the name of heritage and can at times assume heated or emphatic tones. Concepts such as 'heritage', 'authenticity' and 'tradition', appear in our daily affairs with such frequency that they have become absorbed into the lexical sphere of common sense.

${ }^{7} /$ refer to the political and administrative roles that the persons mentioned exercised during the period in which these volumes were published. 
territory. The value of the Historical Workshops is that of "workshops of memory, precious places of history, bearers of the city tradition" presented as an example "of an entrepreneurial and mercantile tradition that is typically Milanese". Tradition, in his discourse, becomes "the starting point for growth and development today" and, although he recognises that the businesses have had to reinvent themselves over the course of time, he highlights how they have remained "faithful to their roots" and can therefore be considered as "a heritage for the entire city and the people of Milan." The programmatic aims of the Register of Historical Shops are also reflected in his words:

[The Historical Workshops are] an old and new 'bridge' between the economy and sociality, and between identity and innovation (...). It is essential (...) to preserve these places, because they not only contain the identity of the past, but provide the right balance to a modern city that has become fast, fragmented, globalised and multicultural, and is likely to lose its way if it forgets its own history and a sense of belonging based on a way of being, a 'civic' dimension (Carlo Sangalli, 2006).

In the second volume (2007) it emerges that the privileged holders and guardians of this "tradition" conveyed and valued by the Register of Historical Workshops are, above all, the restaurants and trattorias. Unlike the pages featuring the other activities, the descriptions of the restaurants and trattorias in the 2007 volume each end with a recipe, which, as Tiziana Maiolo writes, "we gladly offer to the inhabitants of Milan and all those around the world who might wish to remember this as the true Milan metropolitan area" (Tiziana Maiolo, 2007). The third volume (2008), in my opinion, reveals the closest links with the urban territory and, in a certain sense, constructs it as a social and relational space. The inside of the book's dust jacket features a drawing of a map of the city taken from a period print, to which the locations of all the Historical Workshops in the centre of Milan have been added. The words of Giovanni Terzi, Councillor for Productive Activities, in the opening pages of the volume, also seem to move in this direction:

In our memories, buildings, monuments, shops and premises tend to lose their original purpose and become transformed, through history, into fragments of daily life. In this perspective, typical of Milan, the historical workshops of the capital of Lombardy provide a valuable record of culture and tradition. (.....). The main focus of the 2008 volume is the Galleria Vittorio Emanuele. This symbol of Milanese commerce and salon of the Ambrosian capital was chosen to represent the recognition of 35 'new' workshops and retrace the history of those identified over the previous years (Giovanni Terzi, 2008).

The fourth volume (2009), the cover of which is printed with a map of the city of Milan, and the fifth (2010) also reaffirm the value attributed to the Historical Workshops as places where tradition and the model of a business aimed at enduring over time coexist in perfect harmony. As Carlo Sangalli writes: "Each of these workshops and stores, (...) contains a history formed by years of effort, a 'shared' history of creativity, based on the personal skills of entrepreneurs who managed over time to create an authentic model of development" (Carlo Sangalli, 2010). This creative and effective role in terms of the long-term economic management of these activities is also reiterated by Giovanni Terzi, who describes the situations of the Historical Workshops in the economic fabric of the city, which, in those years, was at the start of a long economic crisis: "In this critical current situation, rebirth can indeed come from traditions, craft skills and the attention to so many details, which, for centuries, our historical workshops have preserved and handed down from one generation to the next". The fifth and final volume (2010), in addition to speeches by the Councillor for Productive Activities and the President of the Chamber of Commerce of Milan, also includes the words of the then city mayor, Letizia Moratti. In the documentary accompanying the fifth volume of "Historical Workshops of Milan", entitled "There are some stories that shouldn't end", immediately after a rapid succession of black and white photos showing some of the shop windows of the Historical Workshops and images of working life in the city, Letizia Moratti describes the Historical Workshops as both "identity" and "tradition":

Places with the authentic feel of Milan. The streets of our old city centre remind us of names from this tradition (...). This is tradition; this is an identity that stretches from the Middle Ages down to the present day. I have wonderful memories associated with the Historical Workshops; I remember, for example, going to eat ice cream at Viel on summer evenings as a young student, or accompanying my grandmother to have her hair done at Gallia-Peter. A historic patisserie, a prestigious tailor's shop or an old craft workshop are beautiful places to visit, both for tourists as well as for us citizens of Milan. But I believe there is something more than this. The Historical Workshops are also an element of social cohesion, because they help to strengthen our pride as citizens and our identity as the people of Milan (...). These places will be able to rebuild the community in the city of Milan, as a city that can be found behind the neighbourhood shops and in and around all the Historical Workshops. This is a very important project, so love these Historical Workshops; to love the Historical Workshops means to have a little bit of love for the history of this city and also for ourselves (Letizia Moratti, 2010). 
The businesses that are recognised receive a plaque and a scroll certifying their membership of the Register of Historical Workshops of the City of Milan, which, as the municipal resolution states, confirms their "cultural heritage status". The plate and scroll are presented during a ceremony held every two years in a room in Milan City Hall. From an anthropological perspective, the plate and scroll are a material representation of the fact that the business belongs to the social and economic fabric of the city of Milan and has become a symbol and guarantee of the values that these policies seek to convey.

In April 2013, during the ceremony for the recognition of the 37 Historical Workshops for 2011 and 2012, the Councillor for Trade, Franco D'Alfonso, declared these businesses, which have helped shape the economic landscape of the city, as genuine "places of memory", "an authentic heritage of professionalism and traditions handed down from one generation to the next" and "a heritage that is visible to all but often goes unnoticed". On the same occasion, Gianroberto Costa, Secretary-General of Confcommercio Milan, stressed that the businesses listed in the Register of Historical Workshops are "testimonies and the backbone of our civil life" and Dario Bossi, board member of the Chamber of Commerce of Milan, defined them as the image of an entrepreneurial spirit that has "managed to make tradition the point of departure for present-day growth and development," and as "precious places in the local area where human relations and indelible social principals are upheld. They are living pieces of our history and landmarks to be protected and promoted"8.

The institutionalisation of the Register of Historic Workshops, and the political discourses associated with it, are building a social tradition in a given territory and thus not only defining the borders of the territory, but also some elements of what I described as the "economy of memory". Restaurants and trattorias occupy a special place in the overall picture. From a quantitative point of view, the "merchandise category" of places where food is prepared "restaurants", "inns", "trattorias", "pizzarias") is the most represented among the businesses recognised as Historical Workshops.

These discourses show the political will to give the Historical Workshops a value based on the coexistence of the business enterprise aspect with the representation of a lost past, an entrepreneurial response to the nostalgia caused by a sense of loss of identity. With the restaurants, trattorias and inns, the economy of memory is based on the desire for discovery of local identity through the consumption of food in a particular place. The restaurateurs negotiate the values of their respective historical workshops in their daily work: their discourses are focussed on the material aspects of the activities included in and required by their work. In various ways they are trying to cook and serve memory discourses.

\section{Historical Workshops and Contemporary Restaurateurs}

The decision to eat out transforms the events associated with the consumption of food, placing them within a social arena composed of complex dynamics. An analysis of these events should also examine the setting in which they occur. Restaurants, through their decor, lighting, tableware and arrangement of tables and chairs - as well as the presentation of the food - seem to have a deep relationship with human emotions and become a metaphor for how we should feel when eating a certain dish in a particular place (Finkelstein, 1989). The customers' feelings, reified and made into consumer goods, are certainly an important part of the "economy of memory" and deserve a more detailed analysis, however, I prefer to focus attention on the discourses of the restaurateurs and the negotiation of the values they attribute to their activities with those proposed in the public sphere of political discourses.

The restaurants listed in the Register of Historical Workshops are very different from one another: what they have in common, at an initial level of analysis, is merely their presence in the economic and social fabric of the city of Milan for a minimum period of fifty years and, of course, the fact that they are all identified as places intended for the consumption of food. Having to deal with such a varied ethnographic scenario, I could not help notice how the Milanese restaurateurs attribute multiple values to their activities and the profound link these have with their own life stories, places, family traditions, the preparation of certain foods and the effort spent "searching" for raw materials.

Augusto (1942) is the co-owner, with his son Paolo, of the restaurant Papà Francesco, now on Via Tommaso Moro, near the Scala Theatre. Sardinian by origin, from a "seafaring" family, he told me that the value he sees in the restaurant is deeply linked to his own personal history and that of his family. Born in Sardinia, Augusto moved to Tuscany

\footnotetext{
${ }^{8}$ The statements of D'Alfonso, Crosta and Bossi are reported in the article that appeared in "Il Giorno" on 15 April 2013 , entitled "Historical workshops in Milan, the list gets longer: 37 more. The authentic heritage of the city". The article can be found through the following link http://www.ilgiorno.it/milano/cronaca/2013/04/15/874014-botteghe-storiche-premiazione-nuove-37-pisapia-patrimonio.shtml (Last accessed 5 December 2015).
} 
at an early age to begin his studies at the Capannina di Franceschi hotel school in Forte dei Marmi (Tuscany), and then worked for a long time in Rome, first as a chef for Dino de Laurentis and then for the Dukes Serra. When he arrived in Milan in the 1960s, he worked in several restaurants in the city, always in the kitchens. Augusto explained to me that the dishes served in his family's restaurant are the result of his experience of life working in the restaurant business, even though he is no longer the only person who cooks:

The menu in Papà Francesco reflects my life, I began to make the dishes featured in it when I was a young chef, and then I learned others over the years, borrowing tricks of the trade... whenever I saw someone in the crew who was better at doing certain things, I always tried to learn them. (...) we also have Sardinian fregola, it's a simple dish... my mother raised us on it.

Paolo, Augusto's son, also confirms that the food prepared and served in their Historical Workshop is not exclusively linked to the traditional cuisine of the city of Milan: the ingredients and recipes used (which Augusto has arranged in a book) also provide space for a discourse related to the family's origins and those of Augusto in particular. Paolo described food as a way of knowing a place (not necessarily the place in which it is consumed): "In addition to making the city of Milan known through Milanese cuisine, we also present something of our own land - Sardinia - and our origins... we use food to create awareness".

Urban transformation, together with what the restaurateurs often referred to as the "awareness" of their customers, has certainly contributed to changing the contents of the restaurants' menus. All the restaurateurs of the Historical Workshops stressed that the work of searching for raw materials and contacting a network of suppliers are daily activities in their working life. Not all the Historical Workshops of the City of Milan offer a type of cuisine based on Milanese culinary tradition, although certain dishes considered as "traditional" - ossobuco, risotto alla milanese, costoletta alla milanese and cassoeula - were found in the menus of all the restaurants where I did my research. The restaurateurs, therefore, seem to recognise a specific value in the "traditional cuisine" of Milan, although other aspects emerged during the ethnographic interviews.

Augusto showed me the two floors of his restaurant and explained the paintings to me (received in exchange for lunches from various artists over the years), telling the stories behind some of them. The paintings are a material representation of the relationships that have been created within the restaurant. One of the walls is dedicated to Augusto's "ancestors": "My father is in the centre, my grandfather on the left and my great-grandfather on the right," he told me, pointing at the photographs of three men on the wall at the back of the restaurant. I interpret the presence of the photographs of Augusto's (and, of course, Paolo's) "ancestors" as an attempt to represent the continuity of the family and its tradition within an economic and social fabric - that of catering in Milan - which he sees as increasingly fragmented, uprooted and, in some ways, "strange". He told me that "many people have the money and decide to buy a restaurant, but then sell it after a couple of years and someone else buys it. It's a world like a Laundromat with tokens". Augusto contrasts the temporal precariousness of the world of catering in contemporary Milan with the stability that his family has managed to give to the business. Explaining to me the roles that the members of his family have within the restaurant, Augusto told me:

I have been here with my family for many years, because, as a family, we have given and continue to give our all. I work in here together with my son Paolo, and sometimes my daughter-in-law makes the desserts. Paolo graduated in economics and then came to work in the restaurant. Between fathers and sons there are always disagreements, like in a trade union. I taught my daughter-in-law to make the desserts. When she first arrived here, she told me that she didn't know how to do anything - that's already something, I thought - then when I saw her with hands in the dough, I knew she had the right hands, and from there I was able to teach her and now she occasionally makes desserts. Paolo acts as manager, taking care of the economic aspect and handling the public relations of the restaurant. My wife comes here and gives everyone instructions about what to do and how to do it... she's a great help... if she sees that there are dishes to be washed in the kitchen, she has no problem with rolling up her sleeves to wash and dry. I come here, however, to get on people's nerves in the kitchen and the dining area, I come and work when there are 150 people here and the dishes are not arriving, the 'old guy' (Augusto himself) goes out there, talks with the customer... I'm in the dining area, perhaps one table has been waiting for a while, so I go into the kitchen and tell them to prepare those dishes immediately. I act as a mediator between the dining area and the kitchen, as I also having a great deal of experience of work in the kitchen.

Just as the Historical Workshop Papà Francesco produces a discourse that indirectly links the role of Augusto's 
"ancestors" with the history of the restaurant, Filippo - manager of the Historical Workshop La Collina Pistoiese, in the centre of Milan, a short walk from the Cathedral in the direction of Piazza Missori - identifies his grandparents, Pietro Gori and Saida Benedetti, as the eponymous ancestors of his business. The restaurant, opened by Michele Galeazzi in 1911', was taken over by the Goris in the late 1930s. "My grandfather and some of his seven brothers," Filippo told me, "came from Tuscany and began selling chestnut cake here in Piazza del Duomo, but he already had the idea of opening a restaurant.

The history of the Gori family is bound up in a very profound way with that of the city. Filippo told me stories handed down by his grandmother to his mother - about daily life in the restaurant during the years of World War II, about the division of labour ("my grandfather in the dining area and my grandmother in the kitchen"), about the work activities of the restaurateur and the differences from the work today ${ }^{10}$, and about "importing" a type of cuisine "that the city didn't know" from Tuscany. The pioneering value attributed by Filippo to his family business seems particularly interesting. When talking about the restaurant at the time of his grandparents, in addition to the introduction of cooking methods and raw materials ("original, authentic products... such as game, cold cuts and legumes") to an urban culinary model ("based on pork, Savoy cabbage and lard... because those were the products available"), Filippo also recognises the value of his family business for the fact of having introduced a "new" catering model to the economic fabric of the city: that of the trattoria.

Milanese, Tuscan, Sardinian, or even Italian origin, in general, is not one of the traits shared by all the managers of Historical Workshops of Milan. Tarcisio was born in Brazil to parents originally from Veneto region, and returned to live in Italy after visiting the country on a journey to discover his roots. Telling me about his professional career, he describes it as almost always associated with the world of catering: from when he started as a dishwasher in a restaurant in Rome to when, after returning to Brazil and coming back again to Italy, he worked as a waiter at the Osteria del Comune Antico. Over the past 16 years, he has been a partner and manager of Biffi, one of the oldest restaurants in the city, located in the Galleria Vittorio Emanuele, next to Milan Duomo. The restaurant, which was inaugurated on 15 September 1867 (during the visit of King Vittorio Emanuele II to the arcade name after him), had been opened by Paolo Biffi, the King's confectioner, in 1866. Tarcisio pointed out that cultivating the theme of the memory of the place where his restaurant is located is part of his daily work. Speaking of the relationship with the customers at Biffi, Tarcisio told me he had realised that the value of Biffi was not only linked to the history of the city, but also to the travel memories that customers who ate at Biffi brought home with them. He told me about a day when an American tourist came and asked for a postcard of the restaurant. "This American kid was making a journey to the places that his recently deceased father had visited for his work... it was a journey of remembrance, which he had organised based on the documents that his father had left... and he had discovered that his father came to eat at Biffi whenever he was in Milan." The knowledge that his restaurant is located in a particular spot in the city - where there is a continuous flow of tourists and business people visiting the centre of Milan - led him to emphasise the value of his Historical Workshop in a discourse related to the location and a search for native authenticity, which also influenced the choices of furnishings.

Just imagine, when I had just arrived here, I wanted to get rid of this shade of green, but after hearing these kinds of stories... I no longer felt like changing the colour. Although the building is now 150 years old... and has gone through so many changes, I don't feel like changing this green [of the fabric that has been on the walls for 31 years]. If one day we have the opportunity, I would like to restore the original decor that the place used to have (...) all in wood... with no modern things, because modern things are lost over time, it all passes away (...). "You see those iron columns?" he tells me, inviting me to turn around, "Those are part of the original internal structure of the building: they are 150 years old and I wanted to make sure that whoever comes in here would see them.

The preservation and restoration of the furnishings - for example, by putting up paintings and prints of Piazza Duomo and the Galleria Vittorio Emanuele in various historical moments - as well as the enhancement of parts of the building's architectural structure - the exposure of the iron columns moves the discourse back in time to the search for an original structure, in terms of materials, images and narrative - is aimed at representing the past in order to bring it into the present.

This was my own initiative, because the people who come here want to know the history of the restaurant, and all

\footnotetext{
9 During the interview, Filippo pointed out to me that originally, the premises had probably been a "bodega" (wine shop) prior to 1911, but when presenting the application for approval to the City of Milan, he was unable to locate the necessary historical documentation.

${ }^{10}$ As another restaurateur told me: "Like with all jobs, the name is the same but what you did in the past has nothing in common with what you do today."
} 
these things... but I've only managed to retrace a few elements of the history of the place so far... if I could find other photos, I'd fill the restaurant with them. I see it as enabling people to experience the history of the restaurant, its history in the city... preserving the city. We must keep these things here, we must go ahead as Biffi to preserve the identity of the city. This is all part of the city."

The food served by Biffi seems to reflect this idea of a search for authenticity through a return to the origins. The dishes on the menu include some "alla Biffi" specialities, but are mainly based on an idea of traditional Milanese cuisine and, despite seasonal variations due to the availability of certain products, they do not change on a daily basis, as is the case in other Historical Workshops.

Their geographical location within the urban fabric of the city - with all that this entails from a social, economic and business perspective - certainly makes the narratives of the various restaurateurs very dissonant, even in terms of the value that is attributed to their respective businesses. In the Bicocca district, on the northern outskirts of the city, Edoardo Stipiti (known as Aldo) and his wife, Elsa, both originally from Ponte Buggianese (Pistoia, Tuscany), opened Trattoria Toscana da Aldo in 1950 (see Rimoldi 2013). Luciano and Alberto Stipiti, the current managers and sons of Aldo and Elsa, told me that the restaurant was originally a rotisserie and occupied only about half of its present floor area; over time, their parents expanded the menu and the workers and staff of Pirelli Bicocca would order their food and then eat it in the nearby Casa del Popolo, a short walk southbound along Viale Sarca. Just before the start of the 1960s, the restaurant began to acquire the form that it still has today: the first tables were set up and customers begin to eat their food on the premises. Until the 1980s, the restaurant was attended mainly by workers from Pirelli-Bicocca. Today, it is not so crowded, but certain features have remained unchanged. Even now, the shop windows have very dark glass, with a simple sign above them. The tables, arranged quite close to one another and covered with red and white checked plastic tablecloths, have paper placemats and serviettes. The walls are covered with framed newspaper articles about the restaurant and various awards presented to Aldo ${ }^{11}$ and his trattoria. The flags that hang there include that of Cuba and the peace flag; Che Guevara, from his most famous poses, casts his eyes over the patrons of the restaurant, while the bearded profile of a young Fidel Castro just after the Cuban revolution is immediately noted by anyone who sets foot inside the premises. As Carlo Sangalli noted in the second volume on the Historical Workshops: "Every historical workshop also tells the story of the customers who have frequented it: is a physical and social place that contains the memories of a lifetime" (Carlo Sangalli 2007). Entering the trattoria between noon and three in the afternoon on any day of the week, it is not unusual to find Vito Basilico sitting at one of the tables and often surrounded by other patrons of all ages. ${ }^{12} \mathrm{He}$ would often tell me, "I have known these people [referring to the Stipiti brothers] since 1955, when I first started coming to eat here. When Pirelli opened their gates, we all came here to the trattoria... not just to eat, but to continue discussing what we had been talking about in our meetings." Vito told me that when Aldo first opened his restaurant, all they served was polenta and fried fish; work began at 5:00 am, because at 6:00 am it was already filled with workers coming off the night shift, and continued until midnight, after serving the workers from the 10:00 pm shift. Entering Aldo's on a sunny summer day in July 2013, Luciano greeted me and started telling me about something that had happened the previous day:

\footnotetext{
'Yesterday, two guys came to the door and one of them said: 'You're left-wing, aren't you?' I answered, 'Yes.' Then he said to the other, 'Right, let's go and eat somewhere else.' What do I care if those guys want to go eat somewhere else? We're left-wing."
}

This, in my opinion, shows how eating a meal at Aldo's still has a very deep political and social value, shared by both the restaurateurs and the customers. Looking back to the 1960s, Vito Basilico and Luciano Stipiti recalled the decision by Pirelli to move their gates a few metres further north, from their position right across the street from Aldo's restaurant. Both of them interpreted this as an action by the "employer" to avoid socialisation and the exchange of ideas among the workers and employees. In the words of Luciano: "Pirelli's gates were right there," he tells me, pointing at the exit door and referring to the opposite side of the street, "the workers came here to eat at lunchtime or in the evening, and the company had the gates moved further up [northwards] so that they would no longer have time to come here to eat,

\footnotetext{
${ }^{11}$ Hanging on the central pillar of the restaurant is the Knight's Cross of the Italian Republic for outstanding civil and sporting merit, awarded to Aldo by Sandro Pertini, President of the Italian Republic, in 1982.

12 Vito Basilico (1926), former draftsman employed at the Pirelli Workshop since the 1950s, was one of the leaders of the workers' struggles at Pirelli Bicocca and one of my main interlocutors for my research on the relationship between working memory and urban transformations. See, for example, Rimoldi 2011, 2013, 2014.
} 
because the workers would meet here and talk..." The consumption of the food itself, just like the place where it was eaten and the sociability that was created, are remembered as elements of a contrast between "us" - the workers and employees who took to the streets during that "Hot Autumn" - and "them" - "the employers", who were trying in every way to maintain control over the bodies of the workers so that they would ensure them maximum productivity in a work environment that is often described by former ${ }^{13}$ Pirelli-Bicocca workers as unhealthy and, at times, enslavement. On the same occasion, without missing the chance to inform me that, due to my age, it would be impossible to describe to me the growing "political fervour" of Bicocca in the 1960s, Vito Basilico started talking about his opinion of the contemporary Italian political situation, the meaning of socialism, and those who are "worst off". He emphasised that riding his bicycle along the road from his home to the Trattoria Toscana and eating his lunch there every day was a form of resistance against a present in which he struggles to find his place. As he told me, "I still come here to eat at Aldo's. For me it's a way to keep up the struggle, listening to the conversations of the workers who come to eat here, away from their work places, and also to meet up with old companions: every now and then one of them shows up." The nostalgic eyes of Vito Basilico, and those of the brothers Luciano and Alberto Stipiti, are turned towards the past, to the times of the union struggles. Vito Basilico explained to me that in the 1960s, the sense of political affiliation was much more pronounced and evident than it is today and, similarly, the consumption of food was associated with well-defined socio-political values. As Vito Basilico told me: "This was the kitchen of the revolution, here the political ideas that circulated were nourished with the food that Aldo cooked and refreshed with a glass of red wine". While Vito Basilico was saying these words, Luciano Stipiti looked at him almost in a trance - almost - because with the corner of his eye he followed and directed the movements of his brother Alberto: "Don't give the peppers to Maurizio (a young customer of the restaurant seated at the table next to ours) because he can't digest them!" as if, by saying these words, he wished to reaffirm to me that, even today, eating "at Aldo's" means creating a bond of familiarity.

The changes in the Bicocca district have had a significant effect on the economy of memory on which the construction of the discourses of the Trattoria Toscana da Aldo is based. The city centre, however, over the last twenty years, has gone from being an urban residential space to one that is almost exclusively used for business, tourism and entertainment.

"More than a change of taste, I think it's a change of habits; when you eat a good ossobuco, you can't help saying it's good!" said Luigi, one of the owners of Don Lisander. The "habits" that Luigi describes are part of the processes of urban transformation of the city, of work models and the types of jobs, and of the aesthetic models for bodies.

"Think back to how the shops in Monte Napoleone were twenty years ago! There were little shops... but who can afford to live there now? Like in Via Manzoni, Via Gesù and Via della Spiga there are just the big brands, the big names in fashion or banking. The centre has changed a lot, especially in terms of rental prices. However, even the large groups have started moving their headquarters away from the circle of the old city centre." If food and places do not have a direct relationship - one place does not necessary have one type of food or culinary tradition, as Augusto and Paolo noted - it is undeniable, however, that they have a close relationship, if we consider the clientele of the Historical Workshops. From the windows of their restaurants, the restaurateurs of the Historical Workshops have had a close-up view of some of the changes and transformations that have affected the city of Milan in recent years.

\section{Conclusions}

Although, as I mentioned, food is not the only element in the social life of Milan's restaurants, it does plays a very important role. In general terms, as affirmed by Maura Franchi, food is a good reflection of contemporary traits in that it has become flexible. It "is adapted to the situations in which it is consumed, interwoven with them, used to create varied hybrid phenomena, broken down into ever smaller and transportable portions, dressed up in different forms and continually transformed into something new: a show, a symbol, care, sociability, communication" (2009:11) and, in the case of Historical Workshops, an economy of memory. The reinvention of food as a commodity implies the attribution of meanings that go beyond its organoleptic properties and merge with broader aspects to make it also become a sociocultural product. The value of the food itself is also constantly negotiated by the local institutions and restaurateurs. This shows that the economic relationship of the exchange of food and money, even in its materiality, is also composed of social relationships and cultural expectations that transcend the exclusively economic dimension.

${ }^{13}$ I refer to the group of former workers and union members from Pirelli Bicocca. Their stories comprise the heart of my research on the Bicocca district. 
As Alessandra Guigoni maintains: "Declaring things as heritage means to make them our own, to copyright them, name them or even baptise them, in a certain sense. Therefore it also means to define, categorise and describe tangible and intangible cultural assets empirically, with words, pictures, video and whatever else technology provides us with today" (Guigoni 2009: 174-175). To my mind, enrolment in the Register of Historical Workshops marks the processes described by Guigoni: the title "Historical Workshop of the City of Milan" is added to the name of the business, which becomes the subject and focus of publications and of special attention from the local administration. The values assigned to the Historical Workshops refer to the intention to assimilate the past - or what is perceived of as such - through recourse to the origins as a justification of local policies. The dimensions of space, in terms of a physical and social location, and time, as a justification, build a series of values that fall within the city's economy of memory. In this perspective, the element of memory is crucial from an anthropological point of view, and broadens the economic factor of value, combining it with social and cultural aspects. The discourses of the restaurateurs of the Historical Workshops appropriate these themes but build the economy of memory with discourses of another kind. Inclusion in the Register of Historical Workshops in a certain sense authorises the stories of life and work of the restaurateurs and their families, the urban transformation of the city centre and the outskirts - and consequent change in clientele - and the attention to preserving certain dishes in the menus as constituent elements of the economy of memory, linked to the consumption of food in contemporary Milan.

In conclusion, I believe that the establishment of the Register of Historical Workshops is a good example of inventing a tradition. I realise that it is not difficult to notice the artificiality of this tradition, nevertheless, I am convinced that contemporary anthropology should not underestimate an important fact: the negotiations of the values that various social actors attribute to the Historical Workshops highlight that fact that these are building processes aimed at selfrepresentation and are based on facts and behaviours that belong to the local and individual cultural heritage of those who put them in place.

\section{References}

Appadurai, A. (1988). "How to Make a National Cuisine: Cookbooks in Contemporary India" Comparative Studies in Society and History, 30.1, 3-24.

Badii, M. (2012). Processi di patrimonializzazione e politiche del cibo. Un'etnografia nella Toscana contemporanea [Food Heritage Process and Politics. An Ethnographical Study in Contemporary Tuscany]. Perugia: Morlacchi.

Barberani, S. (2012). "The Poetics of Food Consumption: Alimentary Rhetorics and Creative Practices." Mediterranean Journal of Social Sciences, 3.7, 285-291.

Breiss, D., Sutton, D. (2007). "Starter. Restaurants, Ideal Postmodern Institutions". In D. Breiss \& D. Sutton (Eds) The Restaurants Book. Ethnographies of Where We Eat (pp. 1-13). New York, NY: Berg.

Counihan, C. (2009). A Tortilla Is Like Life. Austin, TX: University of Texas Press.

Counihan, C., Van Esterik P. (Eds) (2013). Food and Culture. A Reader (3rd Edition), New York, NY: Routledge.

Finkelstein, J. (1989) Dining Out: A Sociology of Modern Manners. Cambridge: Polity Press.

Franchi, M. (2009). Il cibo flessibile [Flexible Food]]. Roma: Carocci.

Douglas, M. (1972). "Deciphering a Meal." Daedalus, 101.1, 61-81.

Goody, J. (1998). Food and Love. A Cultural History of East and West. London: Verso.

Guigoni, A. Foodscapes. Stili, mode e culture del cibo oggi [Foodscapes. Contemporary Food Styles, Trends and Cultures]. Monza: Polimetrica.

Graeber, D. (2001) Toward An Anthropological Theory Of Value. New York, NY: Palgrave.

Holtzman, J. D. (2006). "Food and Memory." Annual Review of Anthropology, 35, 361-378.

Le Botteghe Storiche di Milano [The Historical Workshops of Milan] (Volume 1). Milano: Comune di Milano, Camera di Commercio di Milano, 2006.

Le Botteghe Storiche di Milano [The Historical Workshops of Milan] (Volume 2). Milano: Comune di Milano, Camera di Commercio di Milano, 2007.

Le Botteghe Storiche di Milano [The Historical Workshops of Milan] (Volume 3). (2008). Milano: Comune di Milano, Camera di Commercio di Milano, 2008.

Le Botteghe Storiche di Milano [The Historical Workshops of Milan] (Volume 4). Milano: Comune di Milano, Camera di Commercio di Milano, 2009.

Le Botteghe Storiche di Milano [The Historical Workshops of Milan] (Volume 5). Milano: Comune di Milano, Camera di Commercio di Milano, 2010.

Le Botteghe Storiche di Milano [The Historical Workshops of Milan] (Volume 6). Milano: Comune di Milano, Camera di Commercio di Milano, 2011.

Miller, D. (2008). "The Uses of Value." Geoforum 39, 1122-1132.

Mintz, S. W., Du Bois, C. M. (2002) "The Anthropology of Food and Eating" Annual Review of Anthropology, 31, 99-119. 
Montanari, M. (2004). II cibo come cultura [Food as Culture]. Roma: Laterza.

Pratt, J. (2007). "Food Values. The Local and the Authentic." Critique of Anthropology, 27.3, 285-300.

Paxon, H. (2013). The Life of Cheese. Crafting Food and Value in America. Berkeley, Los Angeles, London: University of California Press.

Pomian, K. (1999). Sur l'Histoire [On History]. Paris: Editions Gallimard.

Rimoldi, L. (2011). "Sul marciapiede di viale Sarca a Milano. Storia e storie delle «battaglie» Vito Basilico, sindacalista della PirelliBicocca." [On the sidewalk of Viale Sarca. History and Stories of Vito Basilico, Trade Unionist of the Pirelli-Bicocca factory] Memoria/Memorie, 6.37, 49-72.

(2013). "«The Kitchen of the Revolution» Food and Working-class Memory in the Bicocca Area (Milan, Italy)." Mediterranean Journal of Social Sciences. 4.3, 778-785.

(2014) "Eating Online Discourses: Rhetorics on Food Consumption in Contemporary Bicocca (Milan, Italy)." Journal of Educational and Social Research. 4.1, 469-477.

Sutton, D. (2007). Remembrance of Repasts: An Anthropology of Food and Memory. Oxford: Berg. 